\title{
REFLECTIONS ON SOCIAL MEDIA USE ALONG THE ACADEMIC RESEARCH LIFE CYCLE
}

\author{
Anand Sheombar \\ HU University of Applied Sciences Utrecht, The Netherlands
}

\begin{abstract}
This short paper argues for the need for discussion on the role social media could have in the research life cycle, particularly for Information Systems (IS) scholars. ICTs are pervasive, and their societal impact is profound. Various disciplines including those of social sciences are present in the online discourse and join the public debate on societal implications of ICTs and scholar are familiar with web tools for publishing. Information Systems scholars could not only further explore the possibilities for joining that online discourse, but also could explore the potential social media may have for activities related to the research life cycle. In this paper we do not focus solely on social media as a data collection source but regard their merits as a channel for scholarly communication throughout the whole research life cycle, from the start of getting inspired to conduct a research, finding collaboration partners or funding, through suggestions for literature, to the stage of research dissemination and creating impact beyond the own scientific community. This paper contributes an original approach to research communication by combining the research life cycle with practical insights of how social media can be applied throughout each phase of that lifecycle. We conclude with some questions debating the stance that (future) IS scholars are prepared to become the digital scholar that can manoeuvre well on social media for scholarly communication.
\end{abstract}

\section{KEYWORDS}

Social Media, Scholarly Communication, Research Communication, Open Science, Academic Research Life Cycle

\section{INTRODUCTION}

Social media may change the academic research life cycle. What implications it has on scholarly communication is not clear (Mas-Bleda et al., 2014), but the younger generation of scholars is more used to use those technologies in their personal life and eventually for academic activities. "As researchers adopt new tools and are increasingly encouraged by institutions and funders to reach wider audiences, science communication is changing. In some ways, these new media formats are replicating previous systems, and in other ways, these tools present profoundly new ways of communicating", Mollett et al. (2017) argue. The potential for IS scholars is evident.

When we discuss research communication via social media, we first have to outline the concepts involved. The terms social media, social networks (SNSs), and web 2.0 are often interchanged in usage (Parameswaran, 2007, Iriberri and Leroy, 2009, Zuniga and White, 2009). For this research, social media is defined as a techno-social system for participatory culture, having characteristics like openness, participation, conversation, connectedness, and community. This definition relies heavily on the ideas set forward by Fuchs (2013) and Mayfield (2008). Scholarly communication is defined as "the system through which research and other scholarly writings are created, evaluated for quality, disseminated to the scholarly community, and preserved for future use. The system includes both formal means of communication, such as publication in peer-reviewed journals, and informal channels, such as electronic listservs." (ACRL, 2016).

Research or scholarly communication is often depicted as a lifecycle documenting the steps involved in the creation, publication, dissemination, and discovery of a piece of scholarly research. Lugovic et al. (2015) provide an overview of theoretical models of scientific communication systems beginning with the UNISIST model the UN developed in the 1970s, via the lifecycle model of the scientific communication process by Björk (2005), up to more recent models that socio-technical or information system lens for scientific communication. They suggest a theoretical model distinguishing "primary and secondary experience of 
subjects and objects acting to produce and communicate scientific knowledge" (Lugovic et al., 2015). The academic research life cycle describes the cyclical research process, from idea to implementation to dissemination and back to the idea (Gessner et al., 2017). The academic research life cycle encompasses all activities of academic scholars, which of course include the research and publication activities usually associated with scholarly communication, but also includes, for example, pre-scholarly communication explorative activities, social networking, or teaching activities. In the next section, we elaborate on the use of social media throughout the research life cycle and for what purpose IS scholars could use social media.

\section{SOCIAL MEDIA ACROSS THE RESEARCH LIFE CYCLE}

The CIBER research group conducted a major international questionnaire survey that investigated the use of social media in the research workflow (CIBER, 2012). For their study, they surveyed more than 2000 researchers. They conclude that social media has an impact on all points of the research lifecycle, from identifying research opportunities to disseminating findings at the end. When asked about the use in research of eight categories of social media tools (social networking, blogging, microblogging, collaborative authoring, social tagging and bookmarking, scheduling and meeting tools, conferencing, or image or video sharing), a vast majority (63.4\%) of researchers responded that it use tools in only one or two categories, and only a few researchers are using the full spectrum of social media tools (Nicholas and Rowlands, 2011). Collaborative authoring is by the most popular tool, followed by conferencing, and scheduling meetings, while social tagging and microblogging are the least popular. As main reasons for drivers of social media use in research were mentioned in this study: personal initiative, the technological developments and the need for speed, while the main perceived benefits of social media use in research are an international collaboration, faster dissemination and collaboration of people outside academia. Evidence supports the argument that an online social media presence may influence the researcher's citations (Terras, 2012).

Goodier and Czerniewicz (2013) have adapted the functional building blocks of social media by Kietzmann et al. (2011) to create a diagram to present goals for academics' online presence consisting of seven building blocks of the networked scholar. These building blocks are presence (extent to which you as the scholar are visible to others), sharing (extent to which you allow users to exchange your information), connections (the relevance and appeal of your work to others), identity (the extent to which others can identify you online as a scholar), conversations (extent to which others engage with you and vice versa), groups (the extent of your engagement with communities), and reputation (your online standing and the extent to which you influence others). Together they provide a useful overview of social media for research activities. Ortega (2015) observes disciplinary differences in users and use of social media platforms by scientists. Humanists and social scientists massively populate Academia.edu, while ResearchGate is more popular with natural sciences. These scientific, social networks intend to increase the flow of research information by offering new reputation metrics Rinaldi (2014) argues. These new metrics, part of the various alt-metrics, may be used by grant-awarding agencies or hiring committees. Shuai et al. (2012) observed a correlation between Twitter mentions of publications and increase of the preprints on Arxiv of those papers as well as an increase of early citations. This effect or impact may not be that evident for other social media platforms and activities that are related to alt-metrics (e.g. Facebook likes, blog posts, LinkedIn posts and so forth), cf. Thelwall et al. (2013). This paper avoids exaggeration of the potential of research communication but focuses on the benefit it may bring to the communication activities of scholars.

Kell and Czerniewicz (2017) argue that social media communication "offers new affordances for changing research communication practices". The model they present consists of four stages, starting with (1) conceptualisation, then (2) data collection and analysis, followed by (3) articulation of findings and finally (4) translation and engagement. Within each stage, the forms of scholarly communication may change due to social media communication. We suggest adopting a practical model while considering scholarly communication a subset of the academic research life cycle (Figure 1). For this, we adopt the research life cycle approach from Mollett et al. (2017) for its comparative advantages for understanding the role of social media in a research context. "The framework captures the complexity of science communication today and offers a new way to understand research's relevance to society", Mollett et al. (2017) argue. Their life cycle model, although similar but with fewer stages than the life cycle model used by Nicholas and Rowlands (2011), or less detailed than for example the scientific communication process model provided by Björk 
(2005), is useful for its explanatory power. The research life cycle described by Mollett et al. (2017) builds on previous models and developments in communication and the research process (Weller, 2011, Kramer and Bosman, 2015), and consists of six 'phases' of the research: Inspiration, Collaboration, Primary Research, Dissemination, Engagement and Impact. The authors argue that research has always been a social process, but in the advent of digital technologies, academic researchers are collaborating more with each other and with a broader audience than ever before thereby exploring the use of social media.

Taking the six phases as described in the research life cycle model from Mollett et al. (2017) we can illustrate each phase with social media uses and the reason for those activities (Figure 1). This model states that after the Impact phase a new Inspiration phase starts, so a new cycle starts. We have to emphasise the non-linear and iterative nature of scholarly research (Cooper, 2018) which in practice means that not all stages of the life cycle have the same duration and often scholars go back and forth between those stages. Kramer and Bosman (2015) provide an up-to-date overview of tools used for scholarly communication categorised per phase of the academic research life cycle.

The first phase, called Inspiration initiates the research. Exploring ideas is the primary function in this phase. Social media provide a useful online communications channel for encountering new ideas and having a conversation with a global audience. After having established the research idea, in the second phase, the quest for Collaboration partners may be supported by for example social networks dedicated to researchers.

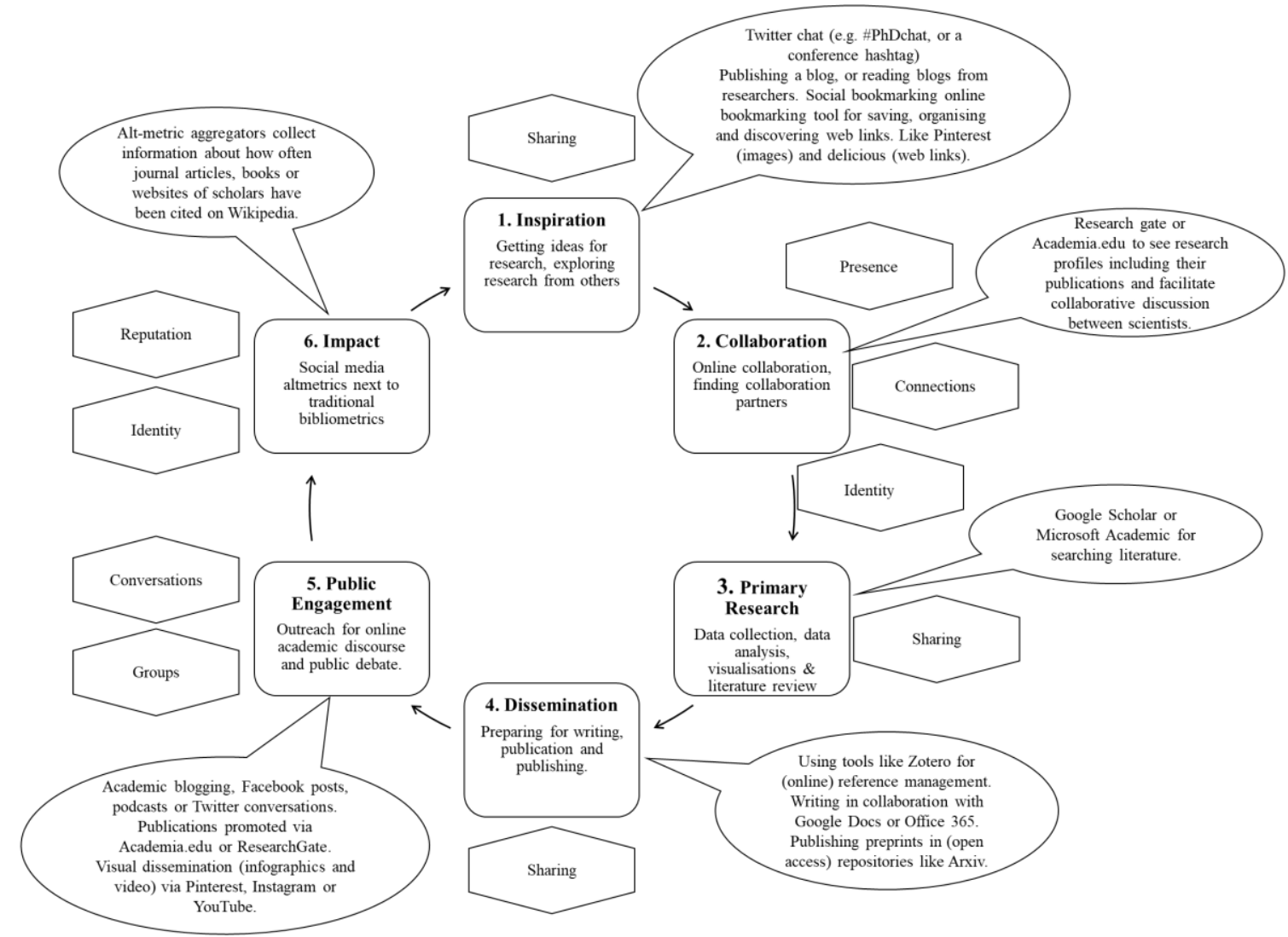

Figure 1. Amalgamation of the phases of the academic research life cycle adapted from Mollet et al. (2017) combined with the most prominent networked scholar building blocks per phase from Goodier and Czerniewicz (2013) depicted as hexagonal tiles, and examples of social media use illustrated by the oval callouts

During the third phase of the primary research activities, the use of online data analysis tools may facilitate collaboration with remote partners. In the fourth phase, writing and preparing for publication are supported with tools for reference management and collaborative writing. In the next phase of public engagement outreach with academic and non-academic audiences can be leveraged with blogs, social networks for researchers or conversations on microblogging platforms. Academic blogging is considered part of an elaborate online academic attention economy which is having a positive impact to readership Thomson 
and Mewburn (2013) argue. In the final phase of impact, tools for measuring social media altmetrics can provide information on impact and outreach. Although a formal definition for altmetrics (short for "alternative metrics") is not available various descriptions are available that elucidate the actual intent of this alternative to traditional bibliometrics. Where bibliometrics as a measure of scholarly output is statistically and mathematically derived from the number of publications, citations and amount of peer reviews (cf. Gingras (2016)), altmetrics are similarly derived from social media activities. Priem et al. (2015) define altmetrics as a diverse group of activities that reflect and transmit scholarly impact on social media which forms a composite trace of impact far richer than traditional bibliometrics. Priem et al. (2015) argue that these altmetrics reveal online scholarly activities and provide alternative or additional means of measuring scholarly impact. A comparison between traditional bibliometrics and altmetrics is illustrated by (Libguides, 2017). After going through all these phases, the academic life cycle starts again with phase 1 where new ideas lead to new research activities and so forth. "Social media affords opportunities for researchers to explore the research process in more social ways, which may in turn help to connect research with its core social remit and commitment", Mollett et al. (2017) argue. The IS researcher can add social media practices to the repertoire needed as a digital scholar. This cycle is complemented with the networked scholar building blocks as suggested by Goodier and Czerniewicz (2013), where the prominent building blocks are assigned to the relevant phase. These building blocks are presence (extent to which you as the scholar are visible to others), sharing (extent to which you allow users to exchange your information), connections (the relevance and appeal of your work to others), identity (the extent to which others can identify you online as a scholar), conversations (extent to which others engage with you and vice versa), groups (the extent of your engagement with communities), and reputation (your online standing and the extent to which you influence others) (Goodier and Czerniewicz, 2013).

As we have discussed the possibilities for scholarly activities and communication by using social media throughout the academic research life cycle, one cannot ignore some of the disadvantages of social media. Online harassment is occurring on the Internet and researchers are not exempt from that kind of harassment. As with private use of the Internet and social media, the professional academic use needs some precautions for protection against online harassment. Furthermore, other disadvantages to being considered are social media considered as time-consuming, distracting, or concerns of too much self-promotion by oneself or by others (Lupton, 2014), or a possible suppressing culture in the academic institution where university managers may try to dictate what is considered acceptable online communication, cf. Bothwell (2019). Supporting information on how to start and choose social media for scholarly online communication are provided by for example Goodier and Czerniewicz (2013), Bik and Goldstein (2013), and Rinaldi (2014).

\section{CONCLUSION}

This paper has contributed an original approach to the field of research communication by combining the research life cycle with insights of how social media can be applied throughout each phase of that lifecycle.

Furthermore, the need for research communication by IS scholars is addressed. We conclude that social media provide additional opportunities for the IS scholar in the academic research life cycle. Of course, there are not only opportunities. There are aspects of social media that need to be prepared for such as online harassment or fear for (online) reputation damage. Many are scholars are well aware of the intricacies of ICTs but being part of the audience and debate in public may be daunting. This paper provides a short overview of possibilities to situate social media in the academic research workflow activities. The paper wants to reflect on the potential of social media for research. Social media is a techno-social environment where the digital IS scholar is not a separate observer but acting participant of the ecosystem. We conclude with a question for future research. Are (next generation) IS researchers as digital scholars well prepared and equipped with the necessary skills to effectively make use of social media for research and scholarly communication in a dynamic society? The impact and (questioning of) value of scientific knowledge are causing public debates where scholars should be prepared for. These become evident in for example the issues arising around digital surveillance and privacy on social media, or the impact of machine learning algorithms and possible embedded bias on society which are of interest for IS researchers. The researcher's voice can then be (additionally) heard in the online public sphere accessible to a broader audience that the traditional publication channels for scientific output. 


\section{REFERENCES}

ACRL. 2016. Scholarly Communication Toolkit: Scholarly Communication Overview [Online]. Association of College and Research Libraries, a division of the American Library Association. Available: https://acrl.libguides.com/scholcomm/toolkit/ [Accessed].

Bik, H. M. \& Goldstein, M. C. 2013. An introduction to social media for scientists. PLoS Biology, 11, e1001535.

Björk, B. C. 2005. A lifecycle model of the scientific communication process. Learned Publishing, 18, 165-176.

Bothwell, E. 2019. Call for sector guidelines on academic freedom on social media [Online]. Imes Higher Education (THE). Available: https://www.timeshighereducation.com/news/call-sector-guidelines-academic-freedom-socialmedia [Accessed].

CIBER 2012. Social media and research workflow.: CIBER, University College London, Emerald Group Publishing Ltd.

Cooper, D., \& Rieger, O. Y. 2018. Scholars ARE Collectors: A Proposal for Re-thinking Research Support.

Fuchs, C. 2013. Social Media, A Critical Introduction, SAGE Publications Ltd.

Gessner, G. C., Eldermire, E., Tang, N. \& Tancheva, K. 2017. The Research Lifecycle and the Future of Research Libraries.

Gingras, Y. 2016. Bibliometrics and research evaluation: an overview. Cambridge MA: MIT Press.

Goodier, S. \& Czerniewicz, L. 2013. Academics' online presence guidelines: A four step guide to taking control of your visibility. University of Cape Town, South Africa.

Iriberri, A. \& Leroy, G. 2009. A life-cycle perspective on online community success. ACM Computing Surveys, 41, 1-29.

Kell, C. \& Czerniewicz, L. 2017. Visibility of Scholarly Research and Changing Research Communication Practices: A Case Study from Namibia. Research 2.0 and the Impact of Digital Technologies on Scholarly Inquiry. IGI Global.

Kietzmann, J. H., Hermkens, K., McCarthy, I. P. \& Silvestre, B. S. 2011. Social media? Get serious! Understanding the functional building blocks of social media. Business Horizons, 54, 241-251.

Kramer, B. \& Bosman, J. 2015. 101 Innovations in Scholarly Communication - the Changing Research Workflow. Poster presented at Force $2015 \mathrm{https} / / / \mathrm{www}$.force11.org/meetings/force2015.

Libguides. 2017. Research Impact \& Visibility: Traditional and altmetrics [Online]. University Library Utrecht University. Available: http://libguides.library.uu.nl/researchimpact [Accessed].

Lugovic, S., Dunđer, I. \& Horvat, M. 2015. The Secondary Experience of an Information System Enabling Scientific Communication.

Lupton, D. 2014. 'Feeling better connected': Academics' use of social media.

Mas-Bleda, A., Thelwall, M., Kousha, K. \& Aguillo, I. F. 2014. Do highly cited researchers successfully use the social web? Scientometrics, 101, 337-356.

Mayfield, A. 2008. What is Social Media? [Online]. Available: http://www.icrossing.co.uk/fileadmin/uploads/eBooks/What_is_Social_Media_iCrossing_ebook.pdf [Accessed].

Mollett, A., Brumley, C., Gilson, C. \& Williams, S. 2017. Communicating Your Research with Social Media: A Practical Guide to Using Blogs, Podcasts, Data Visualisations and Video, SAGE Publications.

Nicholas, D. \& Rowlands, I. 2011. Social media use in the research workflow. Information Services and Use, 31, 61-83.

Ortega, J. L. 2015. Disciplinary differences in the use of academic social networking sites. Online Information Review, $39,520-536$.

Parameswaran, M. 2007. Social computing: an overview. Communications of the Association for Information Systems, 19, 762-780.

Priem, J., Taraborelli, D., Groth, P. \& Neylon, C. 2015. Altmetrics: a manifesto; 2010 [Online]. Available: http://altmetrics.org/manifesto/ [Accessed].

Rinaldi, A. 2014. Spinning the web of open science.

Shuai, X., Pepe, A. \& Bollen, J. 2012. How the Scientific Community Reacts to Newly Submitted Preprints: Article Downloads, Twitter Mentions, and Citations. PLOS ONE, 7, e47523.

Terras, M. 2012. Is blogging and tweeting about research papers worth it? The Verdict. Melissa Terras' blog.

Thelwall, M., Haustein, S., Larivière, V. \& Sugimoto, C. R. 2013. Do Altmetrics Work? Twitter and Ten Other Social Web Services. PLOS ONE, 8, e64841.

Thomson, P. \& Mewburn, I. 2013. Why do academics blog? An analysis of audiences, purposes and challenges. Studies in Higher Education, 38, 1105-1119.

Weller, M. 2011. The Digital Scholar: How Technology Is Transforming Scholarly Practice, London, Bloomsbury Academic.Zuniga, L. \& White, N. 2009. Module Web 2.0 and Social Media for Development. Information Management Resource Kit (IMARK). FAO. 